\title{
Mathematical Modelling and Characteristic Analysis of Solar Photovoltaic System under Partial Shaded Condition
}

\author{
Aditi Kumari Shukla, Abhishek Gupta \\ Department of Electrical Engineering, Swami Keshvanand Institute of Technology, Management \& \\ Gramothan, Jaipur-302017 (INDIA) \\ Email: aditi.shukla1991@gmail.com, abhigupta@skit.ac.in \\ Received 26.02.2021, received in revised form 04.05.2021, accepted 04.05.2021
}

\begin{abstract}
The renewable energy sector has the ability to provide solutions to the persistent power problems facing developing countries. Various renewable energy sources are used to solve the power shortage problem in India. In recent years, the amount of power generation has increased dramatically but the industry is promising for domestic organizations, distribution networks and transmission networks, and the financial situation is slow and influential. India has 450,000 kilowatts of hydroelectric power and the installed capacity of wind power is 230,000 kilowatts, but there is almost no level of renewable energy power generation. Therefore, India has a high level in this field [1]. The goal is to $100 \mathrm{GW}$ of renewable energy. Operational efficiency improvement methods have been portrayed about using gainful decision of Maximum Power Point Tracking computation for variable irradiance and variable temperature condition [2]. Basic improvement in yield and minimization of losses was practiced using simulation and strategy simulation stage using proposed reasoning. The aim of this work is to made logical model for diode corresponding photovoltaic system in MATLAB programming and analyzed the characteristics. Model of system related solar photovoltaic system was made using partial shading and variable irradiance condition. The Maximum Power Point Tracking point following is done by consistent conductance, pester and onlooker and improved PSO (atom swarm optimization) strategy has been executed in MATLAB.
\end{abstract}

Keywords- Solar Photovoltaic, MPPT, Partial Shading, Grid Connected Solar PV System

\section{INTRODUCTION}

As of late solar, wind, biomass and other sustainable power sources have been of worry because of the expanding a worldwide temperature alteration condition to accomplish. For this situation, the photovoltaic (PV) solar systems in the presentation of enormous on the grounds that a local location of government appropriations. Not withstanding the PV yield control during the evening to stop the sensational changes in the power of the sun radiation and air temperature. In an independent design, the photovoltaic power age system is the most reasonable as a spotless energy source, the battery can be utilized to store coordination during the evening use. For some applications, the electric vehicle's capacity PV modules are progressively normal. India has rich solar energy. The energy assets accessible for local power age and modern use. Diminish costs, improve efficiency and execution of photovoltaic boards over a wide temperature range better of ongoing advancements in photovoltaic innovation. The field has been set up for almost two decades, the boundless utilization of intuitive PV systems to the utility framework of astounding development from independence.There are numerous favorable circumstances of the solar system some of which incorporate appropriation and transmission limit alleviation, top burden shaving, the staggering expense of transmission and distribution (T\&D) system update delayed. In spite of these advantages referenced, photovoltaic network interconnection which must consider that it is a ton of specialized issues to be settled before a dependable wellspring of supply. Solar photovoltaic exhibits (PV system), which is the arrangement to do a ton of the most interconnected photovoltaic modules. By a solitary power module created is little enough for business use, so modules are associated in arrangement are organized in parallel to shape a variety of capacity to the heap. In association module cluster is like the module cells.Again by the intensity of a solitary module isn't adequate to meet the power needs of most down to earth purposes. From the PV exhibit utilizing an inverter changing over DC control into AC power and yields it to the engine, lighting burdens and different burdens. Modules are associated in arrangement to get a greater amount of the appraised voltage, and afterward in parallel to meet the present determination, as appeared in Figure 1[3].

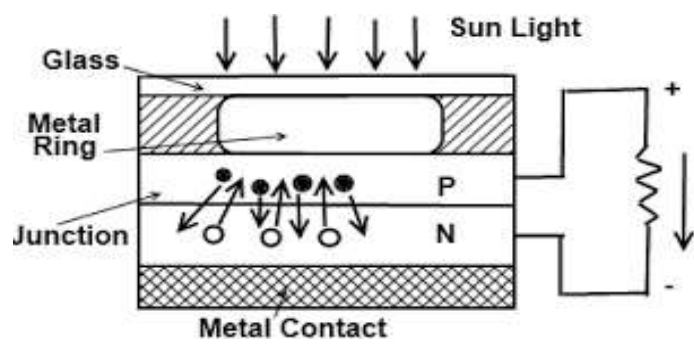

Fig.1 Structure of a PV Cell [3] 


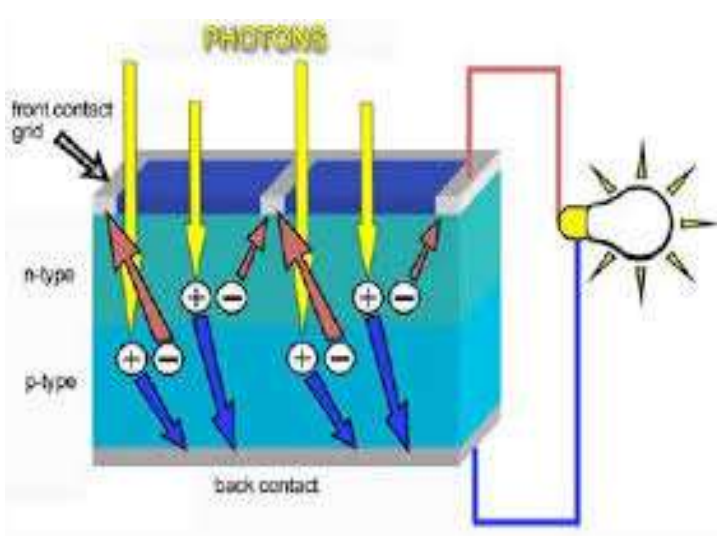

Fig.2 Working of Solar Cell [4]

As is is evident that solar cell or a thin semiconductor wafer, electrical attributes are not the same as the Shockley diode condition layer made of a p-n intersection. Along these lines, a basic equal circuit of the solar cell is associated in parallel with a diode current source. A photovoltaic exhibit (PV system) which are interconnected in arrangement or in parallel of a few modules of the PV cells. Grid connected associated PV system is a system when lattice is associated with PV system and furthermore called utility-intelligent systems. In this kind of system comprises of PV cluster and inverter. Grid connected systems manage AC. Grid connected associated system manages high control applications, so is difficult to store this a lot of intensity in battery[4]. Solar cell is made by two sorts of semiconductor materials one is N-type semiconductor and other is P-type semiconductor material for age of power. Solar cell is producing by various materials.

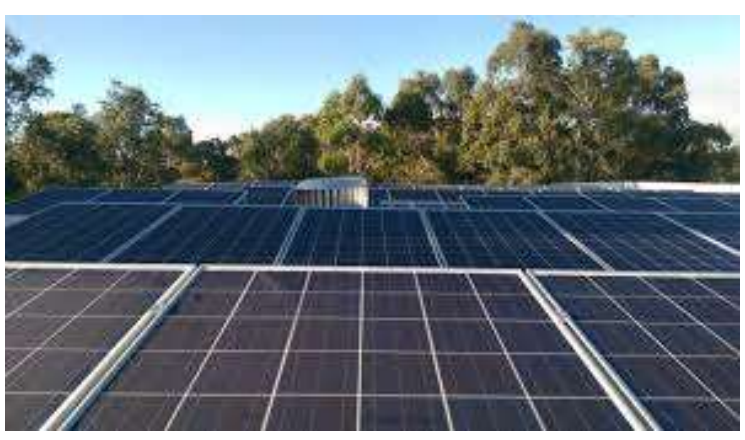

Fig. 3 Partial Shaded Solar PV System[5]

The inverter is utilized to change over the immediate current (DC) created by the solar board into a heap of substituting current (AC). Today, numerous financial specialists available depend on battery associations and system systems. Invertors need to decide the extent of the normal power level to be handled and are perfect with the conditions on the system side[5]. Different segments incorporate JS mounting systems, wiring, switches, disconnectors and system screens.

\section{PARTIAL SHADING CONDITION}

Fractional shading is state of shading of PV module in which low control, shakiness, complex PV and IV bends are made. For the most part, halfway shading happens when certain PV cells on a board or a presentation are camouflaged from direct sunlight.

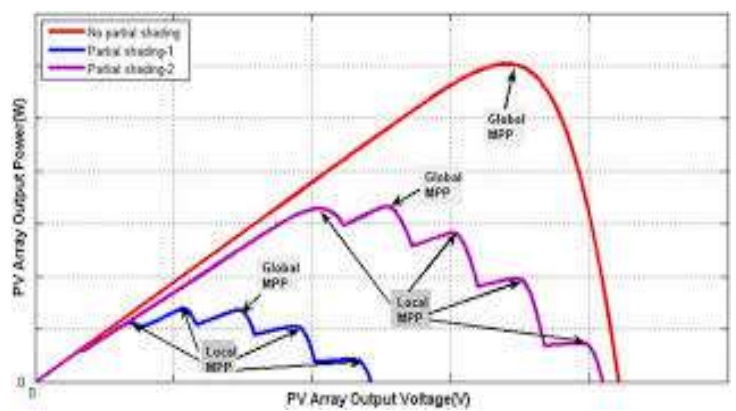

Fig.4 PV characteristics of PV array [6]

Examination shows that most shading happens due to encompassing of trees, overcast spread, building/houses, winged creature droppings, development, water and the tilt reason for solar board. Complete shading made a similar issue yet isn't consider in fractional shading here, trees, structures and mists are the standard reasons of lacking shade. Most extreme force arranges needs toward be inspected and broke down all together as to check the conceivable yield exorbitantly find MPP accessible all through the system at certain condition[7]. Because of this explanation, a MPPT figuring must be related with a system to help in following the MPP in all conditions which should understands an all-encompassing yield and an improved efficiency[8-12]. Above figure shows the two adjoining and one overall most exceptional point through which we can say that general point is accomplish again variance is happen and again neighborhood point is accomplish. Unmistakable most ludicrous force isn't accomplish under fragmentary shading conditions. contrast happen over and over and because of that system efficiency is rotten. So to accomplish most noticeable force point we should apply certain estimations to accomplish the overall most prominent force point[13].

\section{SIMULATION \& RESULT}

The characteristics analysis has been done in MATLAB using SIM POWER SYSTEM toolbox. The two diode model is used to show the simulation of solar cell. The solar panels are created by an array of cell and it is illuminated by variable irradiance across different module in the string. 


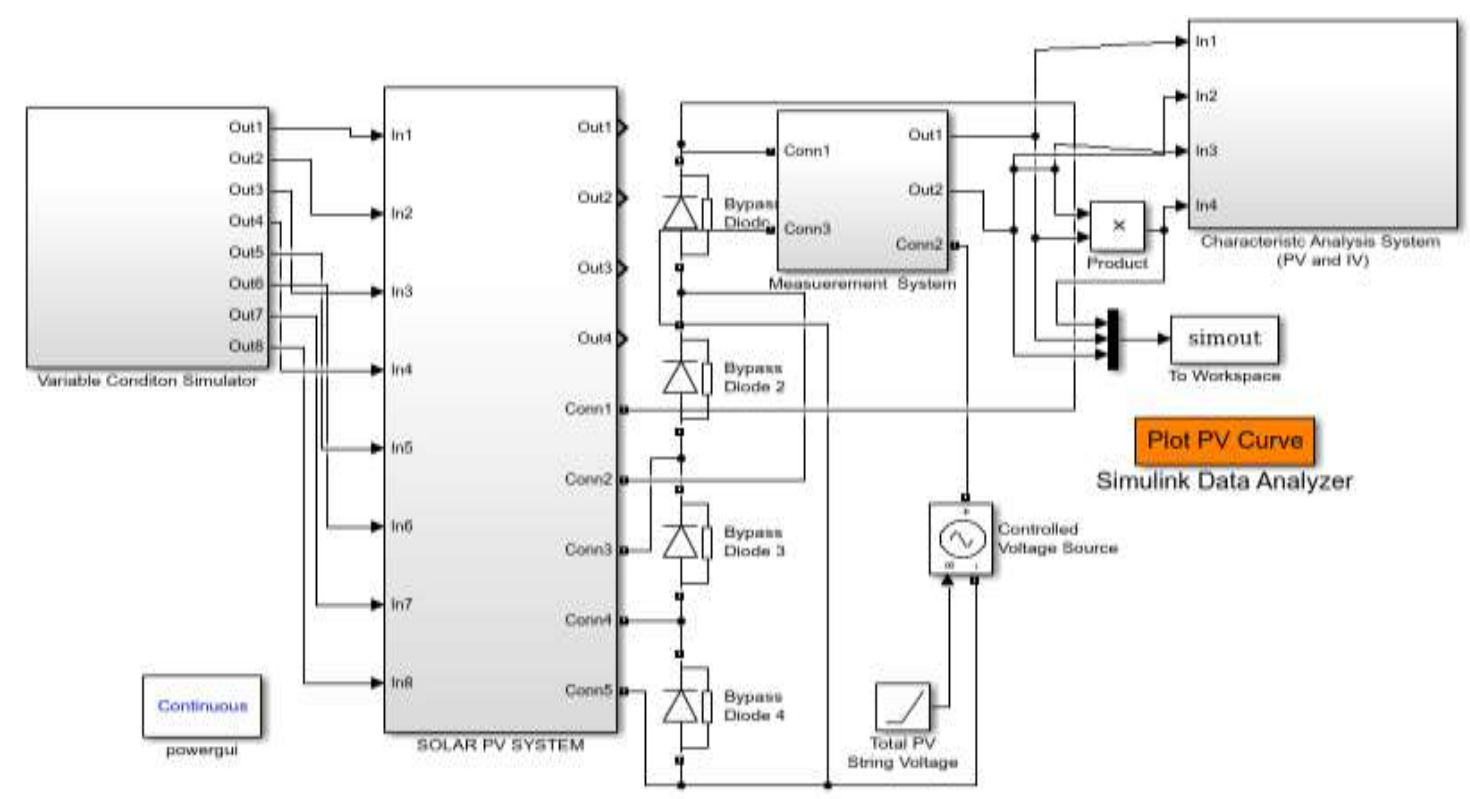

Fig. 4 Model of Partial Shaded Solar PV System

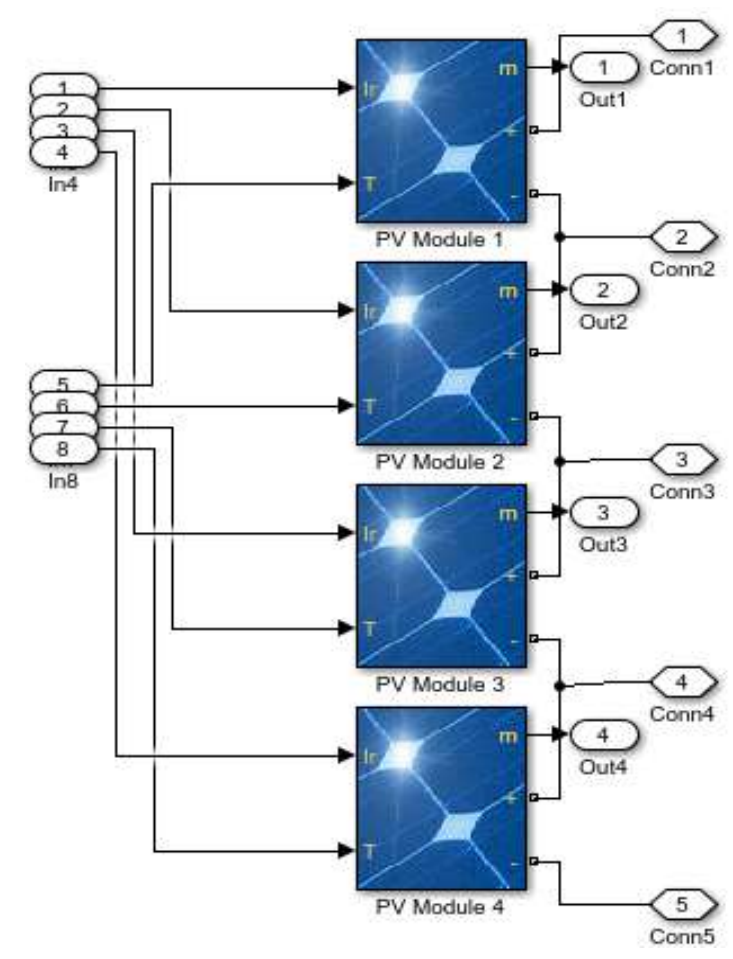

Fig.5 Topology of PV String

Figure 4 denotes the model of partial shading system in MATLAB. It constitutes of a array connected with variable irradiation and variable temperature the output of PV system is connected to measurement system to calculate reading of voltage and current for a simulation time. The matrix of voltage and current is utilized to form the characteristic curve of panel. The characteristics comprise of $\mathrm{P}-\mathrm{V}$ and $\mathrm{I}-\mathrm{V}$ characteristics which are henceforth used to analyse the behavorial model of Solar PV system to identify the point of maximum power from the system[12].

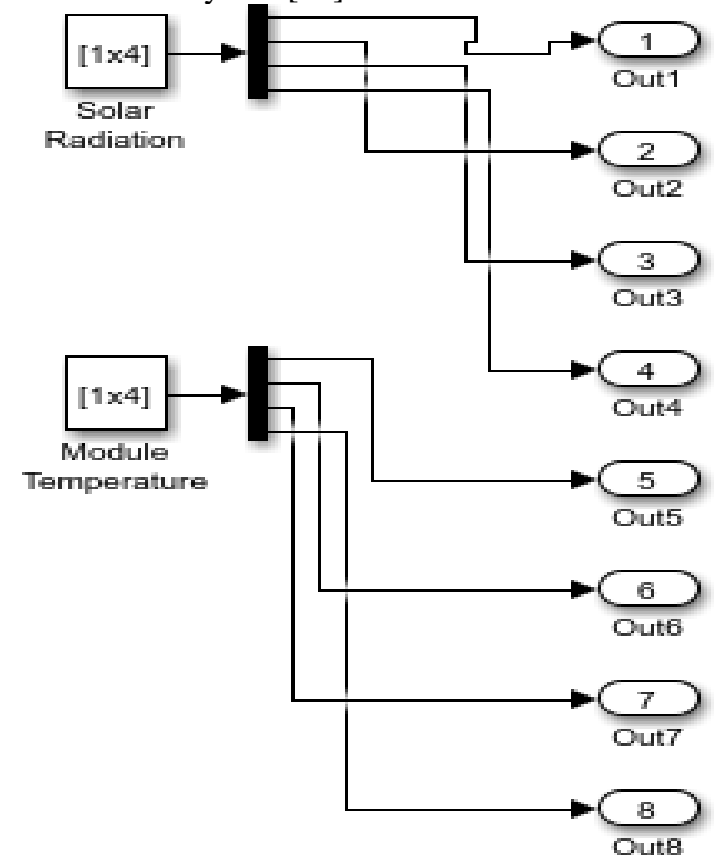

Fig.6 Topology of Variable Irradiance and temperature in PV String

A progressively broad somewhat concealed PV string with $\mathrm{n}$ diverse irradi-ance estimations of $\mathrm{G} 1, \ldots, \mathrm{Gn}, \mathrm{G} 1>\mathrm{G} 2>\ldots>\mathrm{Gn}$, is partitioned into $\mathrm{n}$ sub-strings and their PV module quantities of their substrings are individually $\mathrm{N} 1, \ldots, \mathrm{Nn}$. In light of the simulation results displayed in this area[21]. 


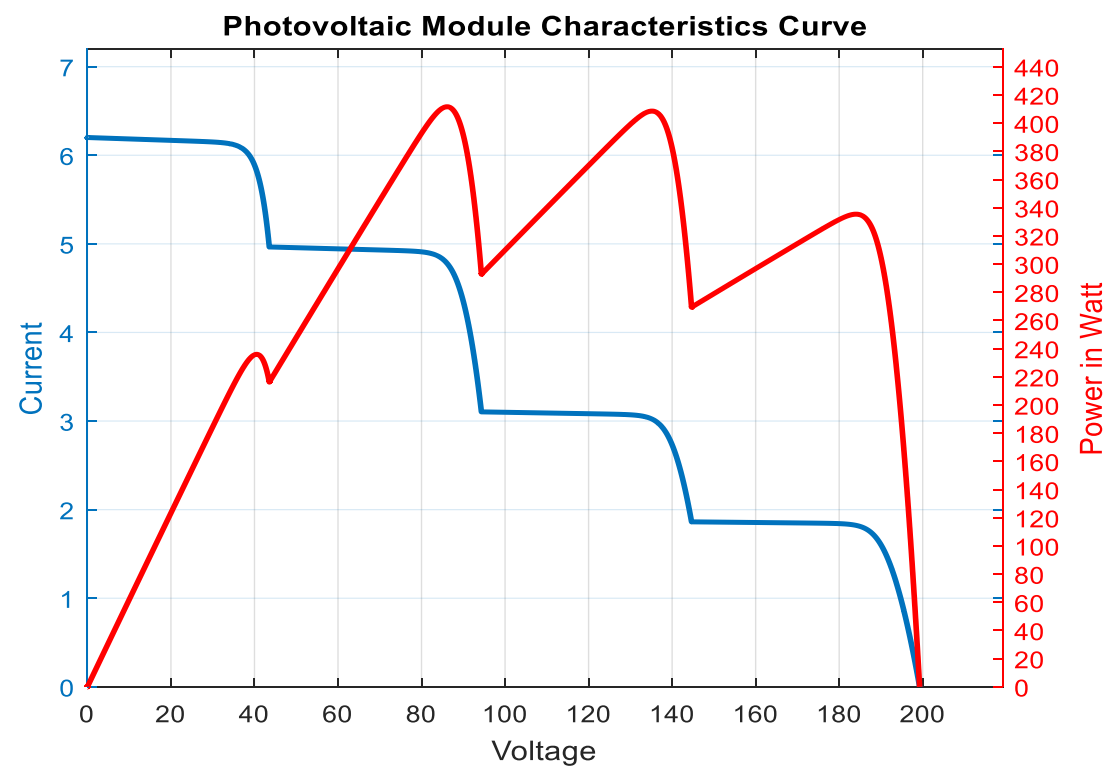

Fig.7 Power and Current Characteristics of Array Under Variable condition [21

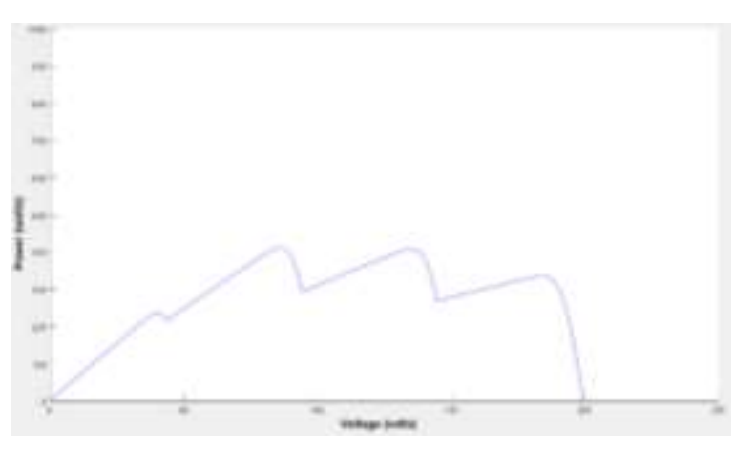

Fig.8 P-V Characteristics of PV Array Under Partial Shading condition [22]

Given a PV cluster comprising of N PV modules are organized into Np PV module strings associated in parallel, each string with Ns PV modules in arrangement, where $\mathrm{N}=\mathrm{Ns} \times \mathrm{Np}$. It is required to acquire the whole $\mathrm{V}-\mathrm{I}$ and $\mathrm{V}-\mathrm{P}$ qualities bends for one to learn and under-stand the conduct of a PV cluster in a mind boggling situation end.

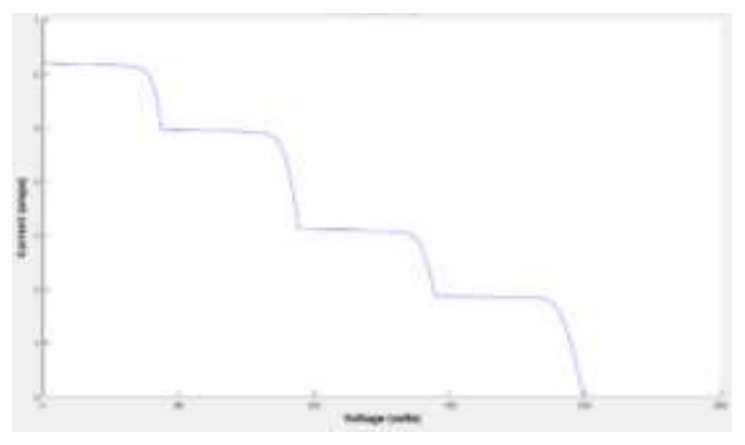

Fig.9 Current-Voltage Characteristics Under Partial Shading condition [23]

A progressively broad somewhat concealed PV string with $\mathrm{n}$ diverse irradi-ance estimations of $\mathrm{G} 1, \ldots, \mathrm{Gn}, \mathrm{G} 1>\mathrm{G} 2>\ldots>\mathrm{Gn}$, is partitioned into $\mathrm{n}$ sub-strings and their PV module quantities of their substrings are, individually, $\mathrm{N} 1, \ldots, \mathrm{Nn}$. In light of the simulation results displayed in this area.

\section{CONCLUSION}

This paper from the outset presents the partially shading condition evaluation with the help of software like MATLAB and PV-Syst for analyzing deficient shading condition. This paper comprises of pv array, mppt controller and boost converter to a battery bank that is evaluated in MATLAB/SIMULINK. The controller helps in reducing the tracking time to find GMPP under partial shading condition. A mathematical model has been explored utilizing MATLAB to get with the impact of variable irradiance and variable temperature on PV and IV curve for solar photovoltiac system. This appraisal is significant in considering partial shading condition influence on voltage variation of MPP. This appraisal will help in MPPT figuring in partial fractional shading situation for efficiency improvement objective in inadequate shading scenario

\section{REFERENCES}

[1] A. Raj, M. Gupta and S. Panda, "Design simulation and performance assessment of yield and loss forecasting for $100 \mathrm{KWp}$ grid connected solar PV system," 2016 2nd International Conference on Next Generation Computing Technologies (NGCT), 2016, pp. 528-533, doi: 10.1109/NGCT.2016.7877472.

[2] T. Esram and P. L. Chapman, "Comparison of Photovoltaic Array Maximum Power Point Tracking Techniques," IEEE Trans. Energy Convers., vol. 22, no. 2, pp. 439-449, 2007.

[3] M. G. Villalva, J. R. Gazoli, and E. R. Filho, "Comprehensive approach to modeling and simulation of photovoltaic arrays,'” IEEE Trans. Power Electron., vol. 24, no. 5, pp. 1198-1208, May 2009. 
[4] Suneel Raju Pendem Suresh Mikkili "Modeling,simulation and performance analysis of solar PV array configurations (Series,Series Parallel and Honey Comb) to extract maximum power under Partial Shading Conditions", Energy Reports Volume 4, November 2018, Pages 274-287 https://doi.org/10.1016/j.egyr.2018.03.003

[5] Z. Cheng, H. Zhou, and H. Yang, "Research on MPPT control of PV system based on PSO algorithm," 2010 Chinese Control Decis. Conf. CCDC 2010, pp. 887-892, 2010.

[6] Li, Shuhui, and Huiying Zheng. "Energy extraction characteristic study of solar photovoltaic cells and modules." In Power and Energy Society General Meeting, 2011 IEEE, pp. 1-7. IEEE, 2011.

[7] M. Miyatake, F. Toriumi, T. Endo, and N. Fujii, "A Novel maximum power point tracker controlling several converters connected to photovoltaic arrays with particle swarm optimization technique,"2007 Eur. Conf. Power Electron. Appl., pp. 1-10, 2007.

[8] C.-L. Liu, Y.-F. Luo, J.-W. Huang, and Y.-H. Liu, "A PSObased MPPT algorithm for photovoltaic systems subject to inhomogeneous insolation," 6th Int. Conf. Soft Comput. Intell. Syst. 13th Int. Symp. Adv. Intell. Syst., no. 1, pp. 721-726, 2012

[9] A real maximum power point tracking method for mismatching compensation in PV array under partially shaded conditions," IEEE Trans. Power Electron., vol. 26, no. 4, pp. 1001-1009, 2011.

[10] Q. Duan, J. Leng, P. Duan, B. Hu, and M. Mao, "An Improved Variable Step PO and Global Scanning MPPT Method for PV Systems under Partial Shading Condition," in 7th International Conference on Intelligent HumanMachine Systems and Cybernetics, pp. 382-386,2015.

[11] P. Lei, Y. Li, and J. E. Seem, "Sequential ESC-based global MPPT control for photovoltaic array with variable shading" ,IEEE Transactions on Sustainable Energy, vol. 2, no. 3, pp. 348-358, 2011.

[12] B. N. Alajmi, K. H. Ahmed, S. J. Finney, B. W. Williams, and B. Wayne Williams, "A Maximum Power Point Tracking Technique for Partially Shaded Photovoltaic Systems in Micro grids" ,IEEE Transactions on Industrial Electronics, vol. 60, no. 4, pp. 1596-1606,2011.

[13] K. Chen, S. Tian, Y. Cheng, and L. Bai, "An Improved MPPT Controller for Photovoltaic System Under Partial Shading Condition," Sustain. Energy, IEEE Trans., vol. 5, no. 3, pp. 978-985, 2014.

[14] J. Ahmed, S. Member, and Z. Salam, "An Improved Method to

[15] Predict the Position of Maximum Power Point During Partial Shadingfor PV Arrays," IEEE Trans. Ind. Informatics, vol. 11, no. 6, pp.1378-1387, 2015.

[16] [15] Hariharan, M. Chakkarapani, G. S. Ilango, C. Nagamani, and S.Member, "A Method to Detect Photovoltaic Array Faults and PartialShading in PV Systems," IEEE J. Photovoltaics, pp. 1-8, 2016.

[17] Uzunoglu, M., and M. S. Alam. "Dynamic modeling, design, and simulation of a combined PEM fuel cell and ultracapacitor system for stand-alone residential applications." IEEE Transactions on Energy Conversion 21.3 (2006): 767-775.

[18] Onar, O. C., M. Uzunoglu, and M. S. Alam. "Modeling, control and simulation of an autonomous wind turbine/photovoltaic/fuel cell/ultra-capacitor hybrid power system." Journal of Power Sources 185.2 (2008): 12731283.

[19] Hidaka, Yasuhito, and Koji Kawahara. "Modeling of a hybrid system of photovoltaic and fuel cell for operational strategy in residential use." Universities Power Engineering Conference (UPEC), 2012 47th International. IEEE, 2012.

[20] Gaonkar, D. N., and Sanjeev Nayak. "Modeling and performance analysis of microturbine based Distributed Generation system,“a review”." Energytech, 2011 IEEE. IEEE, 2011.

[21] Khan, M. J., and M. T. Iqbal. "Pre-feasibility study of stand-alone hybrid energy systems for applications in
Newfoundland." Renewable energy 30.6 (2005): 835-854.

[22] Ali M. Eltamaly, M. S. Al-Saud and A. G. Abo-Khalil," Performance Improvement of PV Systems' Maximum Power Point Tracker Based on a Scanning PSO Particle Strategy." Sustainability 2020, 12, 1185.

[23] Yi-Hwa Liu, Shyh-Ching Huang, Jia-Wei Huang, and WenCheng Liang, "A Particle Swarm Optimization-Based Maximum Power Point Tracking Algorithm for PV Systems Operating Under Partially Shaded Conditions." IEEE TRANSACTIONS ON ENERGY CONVERSION, VOL. 27, NO. 4, DECEMBER 2012

[24] Dileep Krishna Mathi, Ramulu Chinthamalla, "A hybrid global maximum power point tracking method based on butterfly particle swarm optimization and perturb and observe algorithms for a photovoltaic system under partially shaded conditions." Int Trans Electr Energ Syst. 2020; e12543. wileyonlinelibrary.com/journal/etep (C) 2020 John Wiley \& Sons Ltd. 